\title{
A INDUSTRIALIZAÇÃO GOIANA NA MESA DO CONSUMIDOR: ANÁLISE DA CADEIA PRODUTIVA DE ALIMENTOS A PARTIR DA REDE VAREJISTA CARREFOUR
}

\author{
THE INDUSTRIALIZATION OF GOIAS ON THE CONSUMER'S TABLE: \\ ANALYSIS OF THE PRODUCTIVE CHAIN OF FOOD \\ FROM THE RETAILER NETWORK CARREFOUR
}
LA INDUSTRIALIZACIÓN GOIANA EN LA MESA DEL CONSUMIDOR: ANÁLISIS DE LA CADENA PRODUCTIVA DE ALIMENTOS A PARTIR DE LA REDE MINORISTA CARREFOUR
Onofre Pereira Aurélio Neto - Universidade Federal de Goiás - Goiânia - Goiás - Brasil opan.neto@yahoo.com.br
Juheina Lacerda Ribeiro Viana - Universidade Federal de Goiás - Goiânia - Goiás - Brasil juheinalacerda@hotmail.com

Regis Rodrigues de Almeida - Universidade Federal de Goiás - Goiânia - Goiás - Brasil rra_roses@hotmail.com

\begin{abstract}
Resumo
Este artigo tem como objetivo analisar a cadeia produtiva de mercadorias do segmento alimentício, comercializadas pela rede varejista Carrefour Sul. A partir do mapeamento do município de origem de 62 mercadorias, agrupadas em seis categorias, relacionamos a sua distribuição regional com o processo de industrialização de Goiás, o que exigiu uma revisão bibliográfica do panorama da industrialização goiana. Pretende-se, com base na amostragem, identificar quais estados e municípios mantêm relações comerciais com o hipermercado pesquisado e verificar o padrão de localização dos produtos. Verticalizamos nosso estudo na produção de carne bovina, com enfoque na distribuição regional dos estabelecimentos frigoríficos em Goiás. Palavras-chave: Cadeia produtiva, varejo, industrialização goiana.
\end{abstract}

\section{Abstract}

This article has like objective to analyze the goods productive chain of foodstuffs segment traded by retailer network Carrefour South. According to the mapping of the municipality of source of 62 goods, grouped in six categories, we related its regional distribution with the process of industrialization of Goias, demanding a bibliographic review of the panorama of the industrialization. With base in the sample we have intend to identify which States and municipality maintain commercial relation with the hypermarket researched and to check the localization standard of the products. We deepen our study in the production of cattle meat, with focus on regional distribution of the slaughterhouse industry in Goias.

Key words: Productive chain, retail, Goias industrialization.

\section{Resumen}

Este artículo tiene como objetivo analizar la cadena productiva de las mercaderías del segmento alimenticio comercializadas por la rede minorista Carrefour Sul. A partir de la especialización del municipio de origen de 62 mercaderías, agrupadas en seis categorías, relacionamos la su distribución regional con el proceso de industrialización de Goiás, lo que exigió una revisión bibliográfica del panorama de la industrialización goiana. 
Pretendiese, con base en el muestro, identificar cuales Estados y municipios mantienen relaciones comerciales con el hipermercado pesquisado y verificar el padrón de localización de los productos. Profundizamos nuestro estudio en la producción de carne vacuna, con enfoque en la distribución regional de los estabelecimientos frigoríficos en Goiás.

Palabras clave: Cadena productiva, comercio minorista, industrialización goiana.

Introdução

O trabalho tem como objetivo identificar a cadeia produtiva de mercadorias do segmento alimentício ofertadas pela rede varejista Carrefour Sul - localizado no Setor Jardim Goiás, Goiânia. A partir da informação dos municípios de origem (produtores finais) das mercadorias beneficiadas, relacionamos o resultado da pesquisa ao processo de industrialização do Estado de Goiás, analisando a sua distribuição regional. Uma verticalização foi feita para a cadeia da carne bovina, espacializando o seu processo de produção. A escolha por realizar a pesquisa de campo na rede varejista deve-se à importância desse segmento para o comércio. ${ }^{1}$ A rede varejista selecionada, Carrefour, criada na França em 1959, inaugurou sua primeira loja no Brasil em 1975 - instalando-se na cidade de São Paulo - trazendo para o atendimento ao varejo o hipermercado, do qual a rede se considera pioneira (Carrefour, 2010). Em Goiás, a rede foi precursora no segmento de hipermercados, com a primeira unidade inaugurada em Goiânia no ano de 1988. No ano de 2011, a rede atua com quatro filiais varejistas no estado sendo duas lojas em Goiânia, uma em Aparecida de Goiânia e outra em Anápolis; além de dispor de uma unidade atacadista, também localizada em Goiânia.

\section{Aspectos metodológicos}

A pesquisa constitui-se de um levantamento dos municípios de origem de 34 produtos do segmento de alimentos (perecíveis e não-perecíveis) comercializados pela rede varejista Carrefour. De cada produto, foram pesquisadas duas marcas, exceto para os seis produtos que compõem o agrupamento do hortifrutigranjeiro, dos quais selecionamos, para cada um deles, apenas uma marca. Com relação às marcas de carne bovina revendidas pelo hipermercado, foram pesquisadas todas as encontradas. Ao todo a pesquisa abrangeu 62 mercadorias agrupadas em seis categorias, conforme Quadro 1: 
Quadro 1 - Classificação dos produtos pesquisados.

\begin{tabular}{|l|l|}
\hline Classificação & Especificação dos produtos pesquisados \\
\hline $\begin{array}{l}\text { Agrupamento 1: açúcar, cereais, } \\
\text { café e macarrão }\end{array}$ & $\begin{array}{l}\text { Açúcar, arroz, café, farinha de mandioca, farinha de } \\
\text { trigo, feijão e macarrão. }\end{array}$ \\
\hline Agrupamento 2: produtos lácteos & $\begin{array}{l}\text { Creme de leite, leite condensado, leite longa vida, } \\
\text { queijo muçarela e requeijão. }\end{array}$ \\
\hline $\begin{array}{l}\text { Agrupamento 3: condimentos, óleos } \\
\text { e temperos }\end{array}$ & $\begin{array}{l}\text { Azeite de oliva, azeitona, extrato de tomate, maionese, } \\
\text { margarina, óleo de girassol, óleo de soja, sal e vinagre. }\end{array}$ \\
\hline Agrupamento 4: bebidas & $\begin{array}{l}\text { Água mineral, cerveja em lata, refrigerante de laranja } \\
\text { e suco de uva. }\end{array}$ \\
\hline Agrupamento 5: hortifrutigranjeiros & Alface, banana, couve, laranja, ovos e tomate. \\
\hline Agrupamento 6: carnes & $\begin{array}{l}\text { Carne bovina congelada, carne bovina in natura, carne } \\
\text { bovina maturada, carne de frango resfriada e carne } \\
\text { suína congelada. }\end{array}$ \\
\hline
\end{tabular}

Após classificar os produtos, de acordo com suas características em classes de agregados, buscou-se: 1) identificar quais estados/municípios mantêm relações comerciais com o hipermercado pesquisado; 2) verificar perfis e/ou padrões de localização dos produtos, conforme sua classificação; e 3) correlacionar o padrão de localização dos produtos com o aspecto industrial do Estado de Goiás, verticalizado na cadeia produtiva da carne bovina. Para tanto, os dados primários foram associados com dados secundários, utilizando-se a bibliografia sobre a formação econômica goiana. A partir dessa primeira análise, criou-se um material de apoio (mapas, quadros e gráficos) para associar a pesquisa empírica ao processo de industrialização de Goiás.

Panorama da industrialização goiana

No Estado de Goiás, o processo de industrialização tornou-se mais evidente a partir da década de 1970 e intensificou-se na década de 1990, favorecido pelos esforços estatais em atrair indústrias. Entretanto, conforme Borges (1990) e Estevam (1998), é possível observar avanços na produção goiana desde o final da década de 1920, decorrentes das melhorias no transporte e na comunicação que vieram com a implantação da ferrovia.

A partir de 1930, favorecido pela implementação de infraestrutura e crescimento demográfico propiciado pela política desenvolvimentista de Getúlio Vargas de “ocupação dos espaços vazios “centro-oestinos”, o 
Estado de Goiás passou a ter uma nova dinâmica econômica. Entre os fatores que corroboraram para o desenvolvimento industrial goiano, Bertran (1998) destaca: "o êxodo rural ocasionado pela crise do café", que favoreceu a migração do Sudeste para Goiás; "o crescente mercado consumidor interno", propulsionado pela migração de pessoas e capital; e a "redução das importações em função da crise mundial de 1929 e da Segunda Guerra Mundial”. A agricultura de subsistência e a pecuária tradicional que se sobressaíram até o início do século $\mathrm{XX}$ aos poucos cedem lugar para a produção agropecuária destinada à exportação, apesar de persistir a dependência por produtos manufaturados de outros estados, principalmente de São Paulo.

$\mathrm{Na}$ década de 1940, o modelo econômico goiano estimulava a produção de alimentos, ao mesmo tempo em que estava alinhado à política de preenchimento dos "espaços vazios", o que resultou, por exemplo, na implementação de projetos de expansão agrícola, como a Colônia Agrícola Nacional de Goiás (CANG), que originou o município de Ceres - localizado na região centro-oeste do território goiano. ${ }^{2}$

No governo de Juscelino Kubitschek (1956-1961), com a construção de Brasília, aumenta o fluxo de migração para o Centro-Oeste, promovendo uma mudança substancial na infraestrutura goiana, especialmente no que se refere à estrutura rodoviária, estabelecida no plano de metas do governo. A nova capital se configura em um eixo de grandes troncos rodoviários: Brasília-Belém, Brasília-Belo Horizonte, Brasília-São Paulo, Brasília-Cuiabá, Brasília-Barreiras e suas respectivas ramificações, que favorecem a logística do Estado de Goiás para o transporte e exportação da sua produção. A capital federal contribuiu para o aumento do mercado consumidor no Centro-Oeste, impulsionando o crescimento populacional nesta região de 1,5 milhões de habitantes em 1950 para 4,6 milhões em 1970. Além disso, a urbanização da região acabou por propiciar o aperfeiçoamento e a chegada de novas tecnologias para produção, provocando transformações na agricultura, no padrão fundiário, e no espaço urbano.

É ainda na década de 1950 que a nova capital de Goiás se consolida como um expressivo mercado consumidor, em razão de seu elevado crescimento demográfico. Segundo o IBGE, entre 1940 e 1950, a população de Goiânia cresceu 10,8\%, chegando aos seus 53 mil habitantes; já na década seguinte, sua população superaria os 150 mil habitantes (IBGE, 
censo: 1940, 1950, 1960). O crescimento populacional significou um aumento do mercado interno do estado, o que incentivou a produção regional e o desenvolvimento agroindustrial.

No final da década de 1960 e começo de 1970, um fenômeno global, a "Revolução Verde”, desembocou na modernização da prática agrícola no Estado de Goiás e consequentemente acelerou o processo de urbanização e industrialização do território goiano. Conforme dados censitários do IBGE (1970, 1980), a taxa de urbanização saltou de 45,82\% em 1970, para 67,58\% em 1980. Já nos anos de 1970, Goiás se beneficiou da Superintendência de Desenvolvimento do Centro-Oeste (SUDECO) que promoveu o "desenvolvimento de infraestrutura", "transporte rodoviário" e a "criação de celeiros agrícolas" (Arrais, 2004). Além disso, contou com os avanços técnicos promovidos pela Empresa Brasileira de Pesquisa Agropecuária (EMPRAPA), que permitiu a correção dos solos ácidos do Cerrado para a cultura agrícola, impulsionando o crescimento horizontal (expansão da frente agrícola) e vertical (aumento da produtividade, consequência do incremento maciço de tecnologia e biotecnologia na região).

Na década de 1980, o estado passou por uma expansão agroindustrial com a inserção de novos gêneros agrícolas em seu quadro de produção, com destaque para o milho, a soja e a cana-de-açúcar. Ao mesmo tempo, grandes empresas multinacionais adentraram o território goiano. Conforme Castro e Fonseca (1995, p. 5):

A instalação de empresas agroindustriais no Centro-Oeste não é um processo recente, especialmente em se tratando de operações de beneficiamento superficial de produtos como arroz, abate de animais, madeiras, fubá de milho, etc. O que é relativamente novo na região é a presença de empresas agroindustriais de grande porte que estendem as suas operações ao mercado de commodities, de um lado, e ao mercado interno, de outro, integrando em nível regional duas cadeias produtivas, grãos e carnes, com resultados extremamente dinâmicos na região.

A história recente de Goiás - 1990 em diante - é composta pelo surgimento de uma "disputa tributária" com as outras unidades da federação para atrair grandes empresas para o território goiano, a fim de gerar desenvolvimento industrial para o estado, configurado pelas disputas fiscais denominada por Santos e Silveira (2001) como "guerra dos e entre os lugares”. O poder executivo estadual tem utilizado da implementação 
de programas de incentivos fiscais, tais como o FEINCON, o FOMENTAR e o PRODUZIR, ${ }^{3}$ para estimular a industrialização do estado.

No cenário contemporâneo, Goiás acompanhou a dinamicidade das redes produtivas, seguindo a tendência da desconcentração regional que deslocou a indústria da capital para os polos interioranos. O perfil da indústria se diversificou, horizontalizando o tecido industrial goiano com a expansão da tradicional e expressiva agroindústria (tomate, grãos, álcool, carnes), do setor de mineração (níquel, amianto, ouro), da indústria farmacêutica (polo farmacoquímico de Anápolis), a metal-mecânica (metais, autos, maquinário), as empresas de embalagens (plástico e papéis) e de bens "populares" (limpeza, cosmético, fraldas etc.). Essa desconcentração e expansão industrial em Goiás, paralelamente à política de abertura econômica brasileira, implicaram no (re)arranjo do mercado varejista, pois é neste contexto que as grandes empresas do setor começam a expandir seu mercado no Brasil e no território goiano.

\section{Análise da cadeia produtiva dos produtos comercializados no Carrefour}

Com base na amostragem realizada, a unidade Carrefour Sul mantém relações comerciais com todas as regiões geográficas do país, totalizando onze unidades da federação. A região Centro-Oeste se destaca-se com 57\% de participação dos produtos pesquisados, sendo que $83 \%$ deste total são provenientes do Estado de Goiás. A região Sudeste do país também teve uma expressiva participação com $31 \%$ dos produtos pesquisados, sendo São Paulo o lócus de produção e industrialização dos mesmos, detendo $73 \%$ da participação desta região.

As outras regiões tiveram participações pouco expressivas, principalmente a região Nordeste (2\%) e a Norte (1\%). Essa maior circulação no país de mercadorias provindas do Sudeste é um reflexo da própria disparidade histórica da industrialização brasileira. Entretanto, requer atenção o fato de que uma das marcas de queijo muçarela pesquisadas ser oriunda de Conceição do Araguaia (PA), o que comprova o fato de que, segundo a EMBRAPA (2010), nos últimos anos estabeleceu-se a emergência de bacias leiteiras nas frentes pioneiras da Amazônia, havendo, entre os anos de 2001 e 2009, um aumento de mais 50\% da produção de leite na região. Com isso, houve um rápido processo de crescimento da indústria do setor e, logo começou a exportação dessa produção para demais regiões do país. 


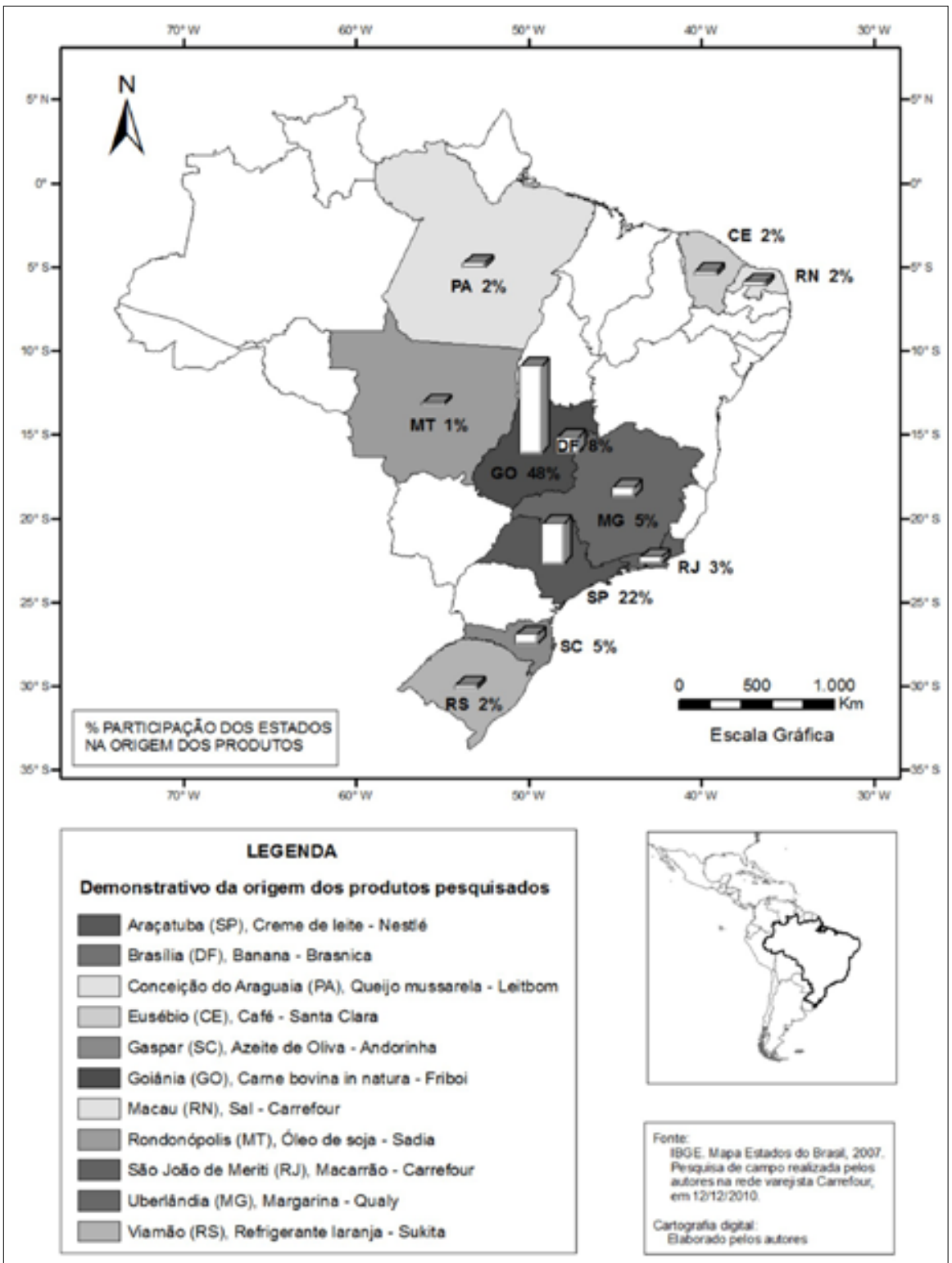

Figura 1 - Brasil: participação dos estados brasileiros na origem dos produtos pesquisados na rede varejista Carrefour (G0). 
No “agrupamento 1" (açúcar, cereais, café e macarrão), 71,4\% das mercadorias provêm do Estado de Goiás, especialmente da Região Metropolitana de Goiânia (RMG) e de Anápolis, totalizando 64,3\% da produção industrial goiana de alimentos nesta classe. Somente o café, uma marca de macarrão e uma de farinha de mandioca são oriundas de outros estados. Ressalta-se, todavia, que produtos como o arroz e o feijão não são em sua totalidade cultivados em Goiás, sendo apenas beneficiados nas indústrias aqui instaladas. ${ }^{4}$ Nos produtos do "agrupamento 2", a maioria novamente está sendo industrializado no Estado de Goiás. Destes produtos, $50 \%$ são provenientes do estado, destacando-se os municípios de Corumbaíba, Uruaçu, São Luís de Montes Belos e Bela Vista de Goiás, sendo este último responsável pela oferta de $20 \%$ da produção láctea do estado. Em relação à participação de outras unidades federativas, cita-se São Paulo - com 30\% de participação, Minas Gerais e Pará, ambos com 10\% de participação na produção deste agrupamento.

A participação menos expressiva que Goiás teve foi no "agrupamento 3" (condimentos, óleos e temperos). Dos dezoito produtos pesquisados, $39 \%$ deles são oriundos de São Paulo, seguido por Santa Catarina e Goiás - ambos com 16\% de participação. Outros estados como Mato Grosso, Rio de Janeiro, Rio Grande do Norte, e o Distrito Federal aparecem apenas com um produto cada. Em relação aos produtos de origem goiana, há o extrato de tomate, a maionese e o óleo de soja, sendo os dois primeiros processados em Goiânia, e o óleo, industrializado em Luziânia.

No "agrupamento 4", de bebidas industrializadas, Goiás aparece, mais uma vez, como grande expoente industrial. Do total de oito produtos desta categoria, 50\% provêm do estado, com destaque aos municípios de Alexânia, Anápolis e Trindade. Depois, aparece São Paulo, com 25\% da produção; seguido de Minas Gerais e Rio Grande do Sul, ambos com 12,5\% de participação.

Os produtos hortifrutigranjeiros, do "agrupamento 5", são oriundos de Brasília-DF e da Região Metropolitana de Goiânia (RMG), ambos com 50\% de participação. Os municípios dessa região são: Aparecida de Goiânia, Bela de Vista de Goiás e Goiânia. A justificativa para esse quadro espacial da origem dos produtos deste agrupamento deve-se à própria característica dos mesmos: são perecíveis em curto prazo de tempo e necessitam de cuidados especiais com as intempéries climáticas (temperatura, umidade etc.). 
O "agrupamento 6" (carnes) foi aquele em que Goiás teve mais destaque, com $84 \%$ de participação. Os produtos deste agrupamento provêm, principalmente, da Região Metropolitana de Goiânia, dos quais $67 \%$ são oriundos do município de Goiânia. Apenas uma marca provém de São Paulo.

Quadro 2 - Relação dos produtos pesquisados conforme município de origem.

\begin{tabular}{|c|c|c|c|}
\hline Produto & Origem & Produto & Origem \\
\hline \multicolumn{4}{|c|}{ Agrupamento 1: Açúcar, cereais, café e macarrão } \\
\hline Açúcar Pérola & Anápolis (G0) & Açúcar EcoAçúcar & Anicuns (G0) \\
\hline Arroz Califórnia & $\begin{array}{l}\text { Aparecida de Goiânia } \\
\text { (GO) }\end{array}$ & Arroz Cristal & $\begin{array}{l}\text { Aparecida de Goiânia } \\
\text { (GO) }\end{array}$ \\
\hline Café Santa Clara & Eusébio (CE) & Café Brasileiro & Araçariguama (SP) \\
\hline $\begin{array}{l}\text { Farinha de mandioca } \\
\text { Nippon }\end{array}$ & Brasília (DF) & $\begin{array}{l}\text { Farinha de mandioca } \\
\text { Araguaia }\end{array}$ & Goiânia (G0) \\
\hline Farinha de trigo Araguaia & Goiânia (G0) & Farinha de trigo Emegê & Goiânia (G0) \\
\hline Feijão Tio Jorge & Anápolis (G0) & Feijão Barão & Goiânia (G0) \\
\hline Macarrão Emegê & Goiânia (G0) & Macarrão Carrefour & São João de Meriti (RJ) \\
\hline \multicolumn{4}{|c|}{ Agrupamento 2: Produtos lácteos } \\
\hline Creme de leite Leitbom & $\begin{array}{l}\text { São Luís de Montes } \\
\text { Belos (G0) }\end{array}$ & Creme de leite Nestlé & Araçatuba (SP) \\
\hline $\begin{array}{l}\text { Leite condensado } \\
\text { Piracanjuba }\end{array}$ & $\begin{array}{l}\text { Bela vista de Goiás } \\
\text { (G0) }\end{array}$ & $\begin{array}{l}\text { Leite condensado } \\
\text { Carrefour }\end{array}$ & Uruaçu (G0) \\
\hline Leite longa vida Italac & Corumbaíba (G0) & Leite longa vida Parmalat & Guaratinguetá (SP) \\
\hline $\begin{array}{l}\text { Queijo muçarela } \\
\text { Piracanjuba }\end{array}$ & $\begin{array}{l}\text { Bela vista de Goiás } \\
\text { (GO) }\end{array}$ & Queijo muçarela Leitbom & $\begin{array}{l}\text { Conceição do Araguaia } \\
\text { (PA) }\end{array}$ \\
\hline Requeijão Canto de Minas & Ituiutaba (MG) & Requeijão Nestlé & Araras (SP) \\
\hline \multicolumn{4}{|c|}{ Agrupamento 3: Condimentos, óleos e temperos } \\
\hline Azeite de oliva Andorinha & Gaspar (SC) & Azeite de oliva Gallo & Mairinque (SP) \\
\hline Azeitona Noppon & Brasília (DF) & Azeitona Carrefour & Alumínio (SP) \\
\hline Extrato de tomate Knorr & Goiânia (G0) & $\begin{array}{l}\text { Extrato de tomate } \\
\text { Carrefour }\end{array}$ & Matão (SP) \\
\hline Maionese Hellmans & Goiânia (G0) & Maionese Lisa & Mairinque (SP) \\
\hline Margarina Qualy & Uberlândia (MG) & Margarina Delícia & Gaspar (SC) \\
\hline Óleo de girassol Salada & Gaspar (SC) & Óleo de girassol Liza & Mairinque (SP) \\
\hline Óleo de soja Soya & Luziânia (G0) & Óleo de soja Sadia & Rondonópolis (MT) \\
\hline Sal Cisne & Cabo Frio (RJ) & Sal Carrefour & Macau (RN) \\
\hline Vinagre Castelo & Jundiaí (SP) & Vinagre Carrefour & Lucélia (SP) \\
\hline
\end{tabular}




\begin{tabular}{|c|c|c|c|}
\hline Produto & Origem & Produto & Origem \\
\hline \multicolumn{4}{|c|}{ Agrupamento 4: Bebidas } \\
\hline Água mineral Schinchariol & Alexania (G0) & Água mineral Lia & Anápolis (G0) \\
\hline Cerveja em lata Skol & Anápolis (G0) & $\begin{array}{l}\text { Cerveja em lata Nova } \\
\text { Schin }\end{array}$ & Itu (SP) \\
\hline Refrigerante laranja Fanta & Trindade (G0) & Refrigerante laranja Sukita & Viamão (RS) \\
\hline Suco de uva Ades & Pouso Alegre (MG) & Suco de uva Nestlé Sollys & Araras (SP) \\
\hline \multicolumn{4}{|c|}{ Agrupamento 5: Hortifrutigranjeiros } \\
\hline Alface Carrefour & $\begin{array}{l}\text { Aparecida Goiânia } \\
\text { (G0) }\end{array}$ & $\begin{array}{l}\text { Laranja comercial } \\
\text { Mendes }\end{array}$ & Brasília (DF) \\
\hline Banana Brasnica & Brasília (DF) & Ovos Carrefour & Bela Vista de Goiás (G0) \\
\hline Couve Carrefour & Goiânia (G0) & Tomate (extra) Toca & Brasília (DF) \\
\hline \multicolumn{4}{|c|}{ Agrupamento 6: Carnes } \\
\hline $\begin{array}{l}\text { Carne bovina congelada } \\
\text { Carrefour }\end{array}$ & Goiânia (G0) & Carne bovina Gold Meat & Cajuru (SP) \\
\hline $\begin{array}{l}\text { Carne bovina in natura } \\
\text { Friboi }\end{array}$ & Goiânia (G0) & $\begin{array}{l}\text { Carne de frango } \\
\text { congelada Bonasa }\end{array}$ & Nova Veneza (G0) \\
\hline $\begin{array}{l}\text { Carne bovina maturada } \\
\text { Swift }\end{array}$ & Goiânia (GO) & $\begin{array}{l}\text { Carne suína congelada } \\
\text { Carrefour }\end{array}$ & Goiânia (G0) \\
\hline
\end{tabular}

Fonte: Pesquisa de campo realizada no Carrefour Sul em 12/12/2010.

Em relação ao universo pesquisado, o Estado de Goiás deteve participação em 48\% dos produtos. Destaca-se, pelo grau de produção, Goiânia, Aparecida de Goiânia - entre outras cidades da RMG, além de Anápolis. Esses três municípios detêm os maiores parques industriais de Goiás e são os mais importantes economicamente para o estado. A RMG, com 66,7\% da produção do estado, merece ênfase também por abranger importantes empreendimentos multinacionais e distritos de agroindústrias, como ocorre em Goiânia, Bela Vista de Goiás, Aparecida de Goiânia e Trindade.

A capital goiana representa o maior mercado consumidor interno para o Estado de Goiás, com mais de 1,3 milhões de habitantes (IBGE, 2010). O fato de ser um mercado consumidor centralizador, dispondo de mão de obra e capital humano qualificado - devido à grande presença de instituições de formação profissional, técnica e universitária - corroboram para a instalação de empresas em seu território, reforçando a participação da capital na origem de produtos de consumo e sendo responsável pelo beneficiamento de $40 \%$ de toda a produção goiana pesquisada. Na região, destacam-se as empresas Emegê, a Araguaia e a transnacional Unilever. 
Detentora de diversas marcas, a Unilever (unidade Goiânia) é responsável pela fabricação de extratos de tomate e produtos a ele similares, maionese, temperos e molhos. Localizada na região norte da capital de Goiás, próxima a importantes rodovias do estado, a BR-153, BR-060 e GO-080, a empresa desfruta de uma logística favorável tanto para a escoação e exportação de seus produtos, quanto para o recebimento de suas matérias-primas.

Aparecida de Goiânia aparece em nossa amostra como responsável por $10 \%$ da oferta dos produtos goianos pesquisados. Possuindo como principal meio de acesso a rodovia BR-153, a sua posição geográfica torna esse município um polo estratégico para investimentos na industrialização, no atendimento de importantes mercados consumidores e na distribuição de produtos. Conta, ainda, com o Polo Empresarial Goiás, o Distrito Agroindustrial de Aparecida de Goiânia (DAIAG) e o Distrito Industrial do Município de Aparecida de Goiânia (DIMAG). Aparecida é sede de empreendimentos no ramo de alimentação como a Brondelli Indústria e Comércio de Produtos Alimentícios Ltda., a beneficiadora de Arroz Tio Jorge, a Mabel, e a Cristal Alimentos.

O município de Bela Vista de Goiás, favorecido pela sua localização próxima aos maiores mercados consumidores do estado (Goiânia e Aparecida de Goiânia), desponta-se como um município produtor de alimentos, principalmente de gêneros derivados da produção animal - com 10\% de participação na produção pesquisada do estado. Seu parque industrial alimentício é destaque entre as principais indústrias de derivados lácteos do Centro-Oeste, com a presença de grupos empresariais como o grupo Laticínios Bela Vista, detentor das marcas Piracanjuba, Pirakids e Salé.

O município de Trindade, com uma de oferta 3,3\% dos produtos goianos pesquisados, destaca-se, sobretudo, no ramo de bebidas. Sendo os Refrescos Bandeirantes, do grupo The Coca Cola Company, juntamente com a Cervejaria Imperial, os principais representantes do setor. Conforme estudo da Seplan (2009), sobre o ranking dos municípios goianos, essa unidade industrial do grupo Coca-Cola é responsável por abastecer os Estado de Goiás e o Tocantins, localizando-se às margens da rodovia GO-060, entre Goiânia e Trindade. Já a Cervejaria Imperial exporta suas bebidas para países como Angola, Moçambique, Guiana Francesa, Estados Unidos, Japão, Guiana Holandesa, Coreia do Sul e Portugal.

Fora da RMG, ressaltam-se os municípios de Anápolis com 13,3\% de participação na produção do estado e Luziânia com 3,3\%. Anápolis é 
uma cidade dinâmica economicamente, possui localização geográfica e logística favoráveis, situando-se no cruzamento de dois eixos rodoviários importantes, a BR-153 e a BR-060, e no ponto de integração da Ferrovia NorteSul com a Ferrovia Centro-Atlântica; dispõe do Distrito Agroindustrial de Anápolis (DAIA), com mais de 120 indústrias e empresas instaladas, e da Estação Aduaneira Interior (EADI), mais conhecida como Porto Seco. ${ }^{5}$ Já o município de Luziânia merece respaldo por ser uma das economias mais fortes e prósperas de Goiás, responsável por 2,4\% do PIB goiano. Luziânia possui um Distrito Agroindustrial (DIAL), localizado a $54 \mathrm{~km}$ de BrasíliaDF, onde estão instaladas grandes empresas como a Bunge Alimentos, Multigran, Friboi-Minuano e Brasfrigo.

Na Figura 2, há um demonstrativo dos municípios goianos e de alguns produtos da amostra pesquisada. Outro aspecto importante a ser mencionado é que as empresas localizam-se em municípios próximos a grandes mercados consumidores, como Goiânia e Brasília, geralmente num raio de $150 \mathrm{~km}$ de distância, e às margens de importantes eixos rodoviários, como é o caso, por exemplo, de Alexânia e Corumbaíba.

O município de Alexânia está situado no eixo Anápolis-Brasília, margeado pela BR-060, onde há intenso fluxo de pessoas e mercadorias. Já o município de Corumbaíba encontra-se na região sudeste de Goiás, na divisa com Minas Gerais, no entroncamento de três rodovias - as GO's - 139 e 303 e a MG-413. Na economia do município, a pecuária leiteira e de corte têm grande peso, e apesar de não estar próximo a grandes centros consumidores, como Goiânia e Brasília, o município localiza-se próximo ao Triângulo Mineiro. Em ambos os casos podemos inferir que a localização geográfica preponderou para a instalação de indústrias nesses municípios.

Alinhado a essa pluralidade industrial goiana, há que se considerar também o perfil agropecuário do estado. Segundo dados da SEPLAN (2009), Goiás é o quarto maior produtor de grãos e de leite do Brasil. O estado possui, também, o quarto maior rebanho de bovinos do país, o quinto rebanho de suínos e o sexto de aves. A seguir, verticalizaremos a produção da pecuária bovina por sua importância para a economia, com considerável produção e participação nas exportações goianas. 


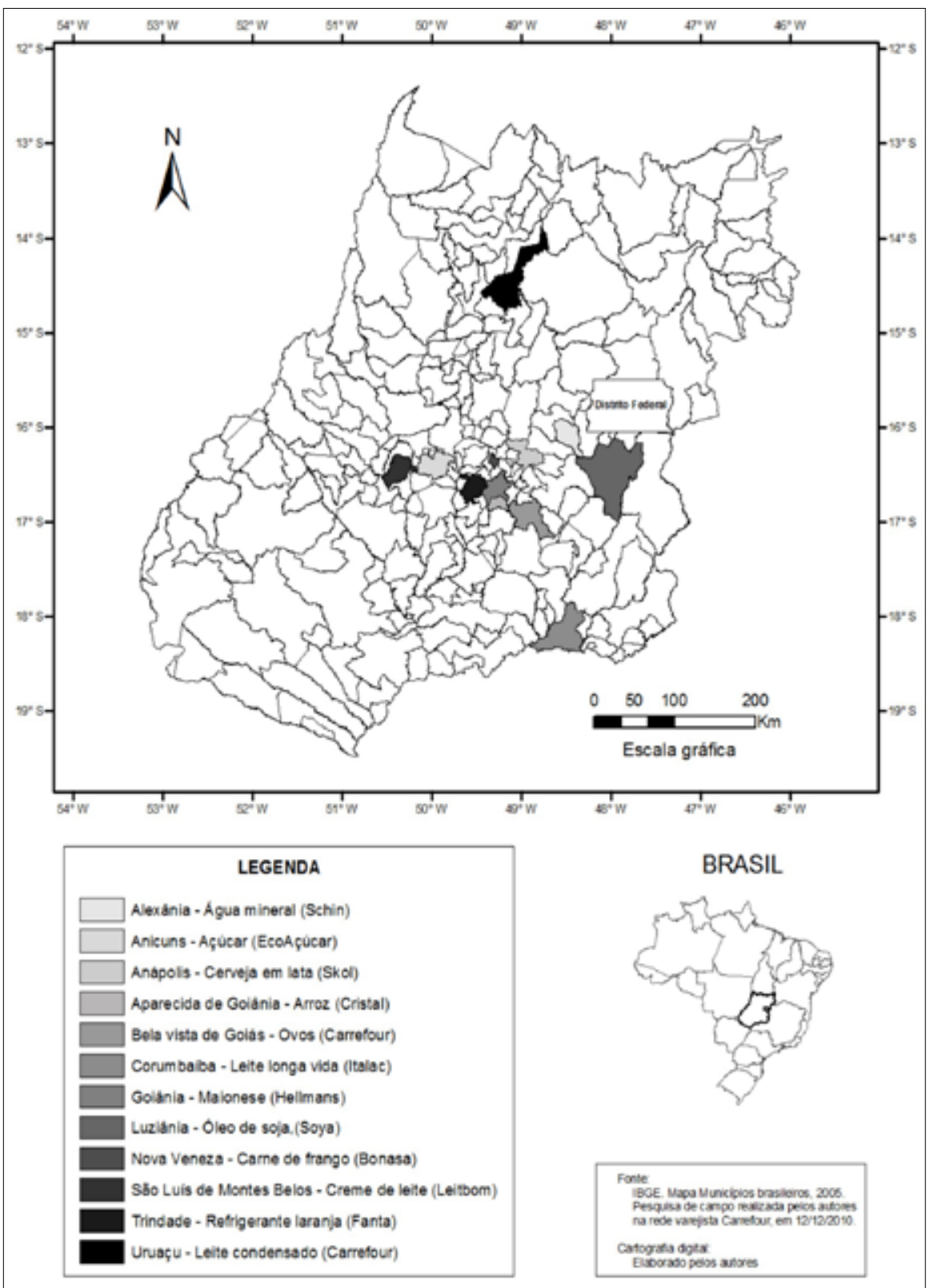

Figura 2 - Goiás: origem dos produtos pesquisados na rede varejista Carrefour (G0). 


\section{A produção de carne bovina em Goiás}

A pecuária bovina, durante o século XIX, expandiu-se sobre o cerrado goiano, penetrando pelos caminhos que anteriormente serviram para o escoamento do ouro. A partir do século XX, o território goiano encontraria na criação de gado o produto tão esperado para equilibrar a balança comercial do estado, em virtude da baixa exigência da pecuária em relação à mão de obra, qualidade do solo, deslocamento da produção e cuidados com a terra. ${ }^{6}$

Desde a década de 1940, a criação nacional de gado apresentou um crescimento em sua produção. Segundo dados do IBGE (1940, 1960), as pastagens goianas aumentaram em mais de 5 milhões de hectares de 1940 a 1960 , e o rebanho bovino em $61 \%$ - passando de 2,9 milhões para mais de 4,8 milhões. Um dos fatores responsáveis pela alta da produção, conforme destacou Prado Júnior (1998, p. 337-339), foi o aumento do consumo de carne, leite e derivados nos grandes centros urbanos do país, sobretudo nas cidades de São Paulo e Rio de Janeiro. Além disso, segundo Borges (2000), o aumento das exportações brasileiras de alimentos, durante a Segunda Guerra Mundial, resultou em uma substancial valorização do preço do boi produzido em Goiás, elevando o preço da arroba da carne nos mercados de São Paulo - estado onde se encontravam instalado os grandes frigoríficos -, o que estimulou a expansão da pecuária.

Historicamente a localização dos frigoríficos na região sudoeste (sobretudo em São Paulo e Minas Gerais) e a precariedade do transporte do gado ocasionavam prejuízos para o produtor goiano, devido à perda de peso do rebanho que tinha de ser deslocado para outros estados para ser comercializado. Conforme Borges (2000, p. 118-119), durante a política de Getulio Vargas, tentou-se criar a "indústria frigorífica estatal", porém a iniciativa fracassou devido à queda de Vargas em 1945. Somente a partir da década de 1960, o estado contaria com a implantação de modernas indústrias frigoríficas, garantido um maior controle sobre a produção de carne em Goiás.

Além disso, a construção de estradas, favorecida pela criação da nova capital federal na década de 1950, beneficiou o escoamento da produção e incentivou a expansão da pecuária no estado. Desde então, a pecuária bovina goiana vem alcançando resultados expressivos na economia, alavancada pelas exportações, sobretudo, para países europeus. 
O número de abate de bovinos no Brasil, assim como em Goiás, cresceu progressivamente até o ano de 2007, incentivado pela demanda do mercado exterior. Com a crise financeira de 2008, que afetou principalmente os Estados Unidos e países europeus - grandes consumidores da carne bovina brasileira -, houve uma redução do volume de abate influenciada pela convulsão pela qual a economia mundial estava passando.

No ano de 2009, de acordo com dados do IBGE, o efetivo nacional de gado superou a marca de 205 milhões de cabeças. Desse total, 10,2\% originário do Estado de Goiás, o que representou 20.874.943, e fez com o que o estado ocupasse o $4^{\circ}$ lugar no ranking nacional de rebanho bovino (IBGE, 2009). Nesse mesmo ano, segundo dados da SEPLAN (2009), foram abatidos 2.538.203 cabeças de gado em todo o estado, um aumento de $24,1 \%$ em relação ao ano de 2000 , porém $15,8 \%$ menor do que o percentual do ano de 2008.

Em virtude da diminuição do consumo, os produtores optaram por reduzir o número de abate na tentativa de conservar o preço da carne, mantendo um equilíbrio da oferta e procura em um nível mais baixo. Desse modo, a pecuária bovina goiana influenciou no preço da carne no mercado interno e externo, em decorrência de o produtor conseguir reduzir ou aumentar o número de abate, controlando a oferta de carne e seu preço.

Apesar da temporária redução ocorrida no número de abates, a pecuária bovina constitui-se em atividade fundamental para os municípios goianos, seja para atender o mercado regional, nacional ou internacional. Em 2010, conforme levantamento do Ministério de Desenvolvimento, Indústria e Comércio Exterior, a carne bovina foi responsável por 13,3\% das exportações do estado, contribuindo com US\$ 537.056 milhões para o seu saldo da balança comercial (MDIC, 2010).

Em Goiás, o rebanho de gado se concentra principalmente na região noroeste e sudoeste do estado, predominando na microrregião de Rio Vermelho, São Miguel do Araguaia e Sudoeste. Considerando os municípios de forma isolada, vale destacar Nova Crixás, maior produtor de gado no estado com 737.585 cabeças, seguido dos municípios de São Miguel do Araguaia com 550.622, Caiapônia com 424.674, e Rio Verde com um rebanho bovino de 412.000 (IBGE, 2009). Segundo a literatura (Borges, 1990; Estevam, 1998), as terras do oeste, sobretudo o noroeste goiano, não despertaram tanto o interesse dos agricultores - devido 
ao maior distanciamento dos principais mercados consumidores, de disporem de menor infraestrutura e serem menos propícios à agricultura que as terras do sudeste goiano -, de maneira que se tornaram reduto para a criação de gado.

Diferentemente do passado, as exigências do mercado bovino determinam que o processamento de carnes seja feito em frigoríficos, devido às questões sanitárias e às próprias cobranças do setor varejista. Atualmente, os frigoríficos goianos estão concentrados na Região Metropolitana de Goiânia (RMG) e em municípios adjacentes, assim como na região do entorno de Brasília.

A capital do estado aparece em nossa pesquisa como uma grande "produtora de carnes", apresentando-se como o município de origem da carne bovina congelada (Carrefour), a carne bovina in natura (Friboi), a carne bovina maturada (Swift) e a carne suína congelada (Carrefour). Entretanto, o rebanho bovino de Goiânia, de 31.000 cabeças de gado em 2009, é insuficiente para atender a sua própria demanda interna. O fato de aparecer como uma grande "produtora de carne" deve-se à presença de frigoríficos na capital goiana e em municípios componentes da RMG, que realizam o trabalho de processamento da carne (corte, resfriamento, embalagem e distribuição) e seu encaminhamento para açougues, supermercados e hipermercados, onde será revendida no varejo para o consumidor final.

Os frigoríficos localizados na Região Metropolitana de Goiânia são atraídos pelo seu mercado consumidor e não pelo seu efetivo bovino. Conforme se verifica com os dados do IBGE (2010), essa região engloba 20 municípios goianos que representam um mercado consumidor concentrado, pois além de conter $36,2 \%$ da população total do estado, tem uma taxa de urbanização de 98\% do total de seus 2.173.006 habitantes, o que a torna atrativa para diversos segmentos de alimentos, entre outros. Apesar de conter apenas 3,2\% do rebanho bovino de Goiás, esse expressivo mercado consumidor impulsiona a instalação de frigoríficos nos municípios que fazem parte da região - em específico os municípios de Goiânia, Goianira, Inhumas, Hidrolândia e Senador Canedo -, fazendo com que nessa região estejam $14,8 \%$ dos frigoríficos do estado. ${ }^{7}$ 


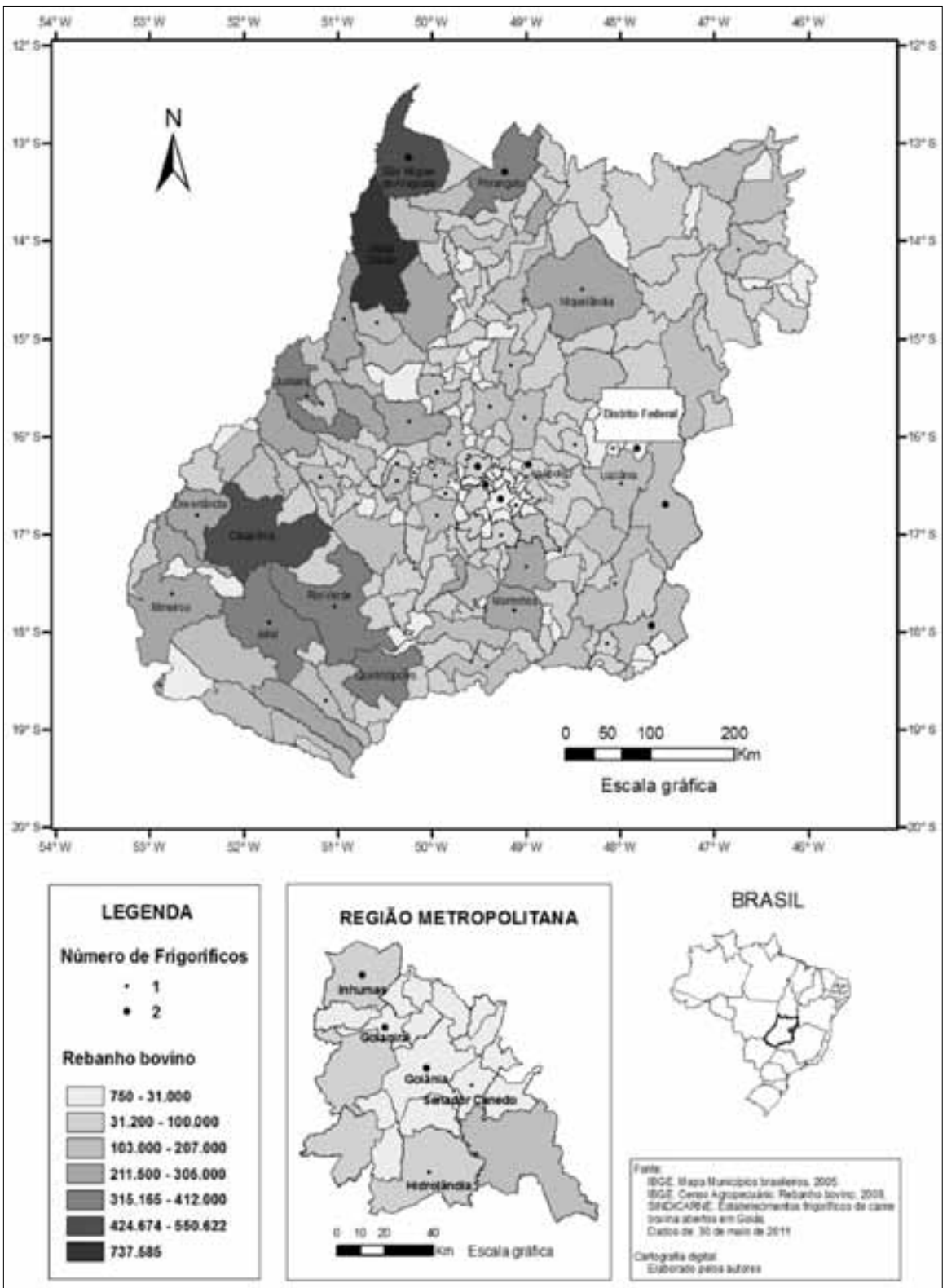

Figura 3 - Estabelecimentos frigoríficos e distribuição do rebanho bovino no Estado de Goiás, em 2009. 
Em Goiás, como dito, a localização dos frigoríficos se deve, principalmente, à proximidade aos principais mercados consumidores, cidades com grande densidade demográfica, e à facilidade de escoamento da carne bovina para a exportação, proporcionada pela malha rodoviária. Porém, há ainda os frigoríficos localizados próximos às principais regiões produtoras de gado, como ocorre em São Miguel do Araguaia com a presença do frigorífico "Goiás Indústria e Comércio de Alimentos Ltda"; em Rio Verde, o frigorífico "MFB Marfrig Alimentos"; em Jussara com o "Frigossara”, em Jataí, o frigorífico "Arantes Abelha Ltda"; em Porangatu com o "Frigonorte Alimentos" e o "HBC Indústria e Comércio de Alimentos"; e em Mineiros o "Marfrig Alimentos" etc.

Observa-se que a produção da carne bovina engloba um processo que perpassa a criação do rebanho, o abate, o resfriamento da carne, a distribuição e o comércio, atendendo às necessidades e exigências do mercado, e firmando um processo que tem despertado o interesse do capital estrangeiro sobre a pecuária nacional. ${ }^{8}$ As multinacionais do segmento de processamento de carne dispõem de um capital financeiro que permite o investimento em pesquisas e aplicação de técnicas que garantem maior produtividade, com a suplementação de rações que aceleram a engorda do bezerro, preparando-o para o abate. Conforme salienta Cabral (2008, p. 32), "a partir de então esses animais seriam engordados em um período de tempo bem inferior que o natural, podendo então ser abatidos precocemente dando lugar a outras remessas para serem engordadas", o que caracteriza uma "industrialização" da pecuária bovina, com a aceleração do processo de engorda e abate para aumentar os lucros.

Alguns frigoríficos nacionais resistiram às investidas do capital estrangeiro e, em vez de serem incorporados pelas multinacionais que compram empresas nacionais para expandir as suas atuações - garantindo o controle do mercado e a eliminação da concorrência -, fizeram o caminho inverso, como é o caso do frigorífico goiano "Friboi-JBS". ${ }^{9}$ Segundo informações da JBS, no ano de 2007 essa empresa consolidou-se como "a maior empresa do mundo no setor de carne bovina, com a aquisição da Swift \& Company nos Estados Unidos e na Austrália” e, no ano de 2009, a JBS diversifica a sua atuação ingressando no segmento de frangos com a aquisição da norte-america "Pilgrim’s Pride" (JBS, 2010). A aquisição de empresas fora do território nacional tem permitido que as empresas brasileiras operem com maior facilidade no mercado internacional. Com 
filiais em países estrangeiros, é possível superar as barreiras alfandegárias e se adequar às exigências do mercado local, contornando obstáculos legislativos, sanitários e protecionistas.

Em setembro de 2009, conforme a Frigo News, a JBS-Friboi anunciou a sua associação com a Bertin Ltda., o que significou uma diversificação para o segmento de produtos lácteos, alimentos para animais domésticos, biodiesel e um aumento da sua concentração no segmento de carnes, garantindo a sua posição de maior empresa de carne bovina do mundo (Frigo News, 2009). Com um maior grau de monopólio, a indústria alimentícia JBS exerce maior controle sobre o preço da carne bovina no mercado, diminuindo a rivalidade entre os produtores à medida que aumenta a sua participação neste segmento.

\section{Considerações finais}

O rastreamento da cadeia produtiva de mercadorias comercializadas pela rede varejista Carrefour confirmou que os municípios goianos de origem dos produtos são os que possuem melhor infraestrutura, localizados às margens de importantes eixos rodoviários e próximos ao mercado consumidor. Tais municípios são locais que receberam uma maior quantidade de recursos de programas governamentais, como o Produzir, Fomentar e o Fundo Constitucional de Financiamento do Centro-Oeste (FCO). Destacam-se os municípios de Goiânia, Anápolis, Aparecida de Goiânia, Bela Vista de Goiás e Luziânia. Esses municípios produtores possuem em comum uma infraestrutura adequada, localização estratégica para o escoamento da produção e estão situados próximos aos grandes centros consumidores.

A mudança do perfil econômico de Goiás, ocasionada pelo processo de industrialização em curso e pelo desenvolvimento do agronegócio, levou a uma concentração da infraestrutura básica em alguns municípios, permitindo que estes ainda recebam o maior volume de investimentos. Em consequência desse processo, é visível a espacialização das indústrias e o beneficiamento da produção em Goiás nas regiões sul, sudoeste e região metropolitana, cujo panorama sobreveio de acordo com os pacotes de investimentos promovidos pelo governo: financiamento da infraestrutura de circulação (malha rodoviária), concessões de crédito e isenção de impostos às empresas e investimentos do setor privado, além dos fatores 
histórico-geográficos. Assim, a industrialização atingiu desigualmente o território goiano.

\section{Notas}

1 De acordo com informações do Serviço Brasileiro de Apoio às Micro e Pequenas Empresas (SEBRAE, 2008), o setor varejista pode ser dividido em dois grandes grupos: um refere-se ao segmento de "super e hipermercados", maior fonte de receita do varejo com $40,7 \%$ da receita varejista e $13,3 \%$ da receita total do comércio em 2005, e o segundo é formado por todo o comércio especializado.

2 Segundo Bertran, a colônia agrícola tinha como objetivo solucionar dois estrangulamentos: "[...] alocar mão de obra liberada pela decadência da cafeicultura (e de maneira mais global pela deterioração das relações de troca entre o velho campo e a nova economia urbana) e criar um frente agrícola comercial interna" (Bertran, 1988, p. 92). Apesar dos resultados positivos da CANG, o estímulo ao desenvolvimento agrícola ocorrera, principalmente, nas regiões sudeste e sudoeste do estado de Goiás, em adequação aos anseios da produção capitalista, uma vez que essas regiões dispunham de melhor infraestrutura e maior aproximação dos mercados do sudoeste brasileiro.

3 O Fundo de Expansão da Indústria e Comércio do Estado de Goiás (FEICON) foi promulgado pela Lei n. 7. 700/1973. A partir desta lei, para garantir o incremento de indústrias no estado, o fundo assentava-se na implantação de infraestruturas básicas (energia elétrica, água, telefone, estradas e auxiliares) para o recebimento das plantas industriais no estado. Em substituição ao FEICON, foi criado em 1984 pela lei estadual n. 9.489, o Programa Fomentar, que visa ao financiamento do imposto (ICMS) a recolher. Posteriormente, o Programa "PRODUZIR", decorrente da implantação pelo governo estadual de políticas de incentivos fiscais, entra em vigor a partir da lei n. 13.591/2000, concedendo o financiamento de até $73 \%$ do ICMS para empresas que se instalassem no território goiano, com o prazo de vigência de 5 a 15 anos e limite em 2020 (Fonseca, 2008).

4 Os dados da Seplan (2010) demonstram que a produção de arroz, nos últimos cinco anos, no território goiano teve uma queda de mais de $16 \%$, sendo que esta produção não consegue abastecer o mercado interno. Em relação ao feijão, houve um pequeno crescimento de sua produção, apenas $3 \%$, valor ainda insuficiente para abastecer o mercado interno goiano.

5 Ver Arrais (2007) e Fonseca (2005).

6 Segundo Borges (1994, p. 154), a opção pela pecuária foi influenciada pela geografia de Goiás, com pastagens naturais, grandes áreas de terras devolutas, pelo fato de o boi se constituir em um produto que se autotransporta e pela topografia favorável.

7 Para esta pesquisa, foram consultados os estabelecimentos frigoríficos de carne bovina existentes em Goiás, considerando um total de 54 unidades; tendo como base de dados o Sindicato das Indústrias de Carnes e Derivados no Estado de Goiás (SINDICARNE). 
8 Desde as vésperas da Primeira Guerra Mundial, empreendimentos ingleses e norte-americanos (Anglo, Armour, Swift, Wilson) se fixaram no Brasil objetivando o fornecimento de carnes ao mercado europeu, de lá para cá outras empresas internacionais vieram para controlar o processo de produção de carne desde a "cria e engorda" até o consumidor final, fixando-se, sobretudo, no Estado de São Paulo (Prado Júnior, 1998, p. 340).

9 Conforme a revista Frigo News (2009), a empresa Friboi, que teve início em Anápolis na década de 1950, iniciou em 2005 a aquisição de empresas estrangeiras com a compra da Swift Argentina, "tornando-se a primeira multinacional brasileira do setor de carnes”. No ano de 2006, com a atuação em vários mercados houve alteração do nome da empresa de Friboi para JBS (José Batista Sobrinho), as iniciais do seu fundador.

\section{Referências}

ARRAIS, Tadeu Alencar. Geografia contemporânea de Goiás. Goiânia: Vieira, 2004.

ARRAIS, Tadeu Alencar. A região como arena política. Goiânia: Vieira, 2007.

BERTRAN, P. Uma introdução à história econômica do Centro-Oeste do Brasil. Brasília: CODEPLAN; Goiás: UCG, 1988.

BORGES, Barsanufo Gomides. Goiás nos quadros da economia nacional: 19301960. Goiânia: Ed. UFG, 2000.

BORGES, Barsanufo Gomides. O despertar dos dormentes: estudo sobre a Estrada de Ferro de Goiás e seu papel nas transformações das estruturas regionais 19091922. Goiânia: Ed. UFG, 1990.

CABRAL, Carmem Lúcia. História, modernização, agricultura e pecuária no sul de Goiás: um estudo de caso sobre o desenvolvimento da agropecuária em Morrinhos - GO - 1970/2000. Monografia de graduação em História apresentado à Universidade Estadual de Goiás - UEG, Morrinhos, 2008.

CAStro, A. C.; FONSECA, M. da G. D. A dinâmica agroindustrial do CentroOeste. Brasília: IPEA, 1995.

ESTEVAM, Luís. O tempo da transformação: estrutura e dinâmica da formação econômica de Goiás. Goiânia: Ed. do Autor, 1998.

FRIGO NEWS. Unidas JBS e Bertin. Ano 1, edição n. 8, outubro, 2009. Disponível em: <www.revistafrigonews.com.br>. Acesso em: 19 de dezembro de 2010.

PRADO JÚNIOR, Caio. História econômica do Brasil. $45^{\mathrm{a}}$ reimpressão. São Paulo: Brasiliense, 1998.

SANTOS, M; SILVEIRA, M. L. O Brasil: território e sociedade no início do século XXI. São Paulo: Record, 2001.

SECRETARIA DE PLANEJAMENTO E DESENVOLVIMENTO DO ESTADO DE GOIÁS. Ranking dos municípios goianos 2009: os municípios mais competitivos do estado. Goiânia: Seplan, 2009, p. 93. 


\section{Sites consultados}

http://www.carrefour.com.br. Acesso em: 3 de dezembro de 2010.

http://www.fieg.org.br. Acesso em: 20 de dezembro de 2010.

http://www.guiamais.com.br. Acesso em: 20 de dezembro de 2010.

http://www.ibge.gov.br. Acesso em: 18 dezembro de 2010.

http://www.jbs.com.br. Acesso em: 18 dezembro de 2010.

http://www.mdic.gov.br//sitio. Acesso em: 25 de janeiro de 2011.

http://www.sebrae.br. Acesso em: 15 de janeiro de 2011.

http://www.seplan.go.gov.br. Acesso em: 20 de dezembro 2010.

http://www.sieg.go.gov.br. Acesso em: 22 de dezembro de2010.

Onofre Pereira Aurélio Neto - Graduando em Geografia pela Universidade Federal de Goiás.

Juheina Lacerda Ribeiro Viana- Graduanda em Geografia pela Universidade Federal de Goiás.

Regis Rodrigues de Almeida - Graduando em Geografia pela Universidade Federal de Goiás.

Recebido para publicação em novembro de 2010 Aceito para publicação em março de 2011 